\section{Retroperitoneal perforation caused by precut biliary access in a Billroth II gastrectomy}

An 81-year-old man was admitted because of cholangitis. He had previously undergone an open cholecystectomy and a gastrectomy with Billroth II reconstruction. Common bile duct dilation was present on transcutaneous ultrasound. An endoscopic retrograde cholangiopancreatography (ERCP) with a therapeutic duodenoscope was carried out. Standard techniques to cannulate the bile duct failed and a needle knife precut (NKP) was performed. Access to the common bile duct
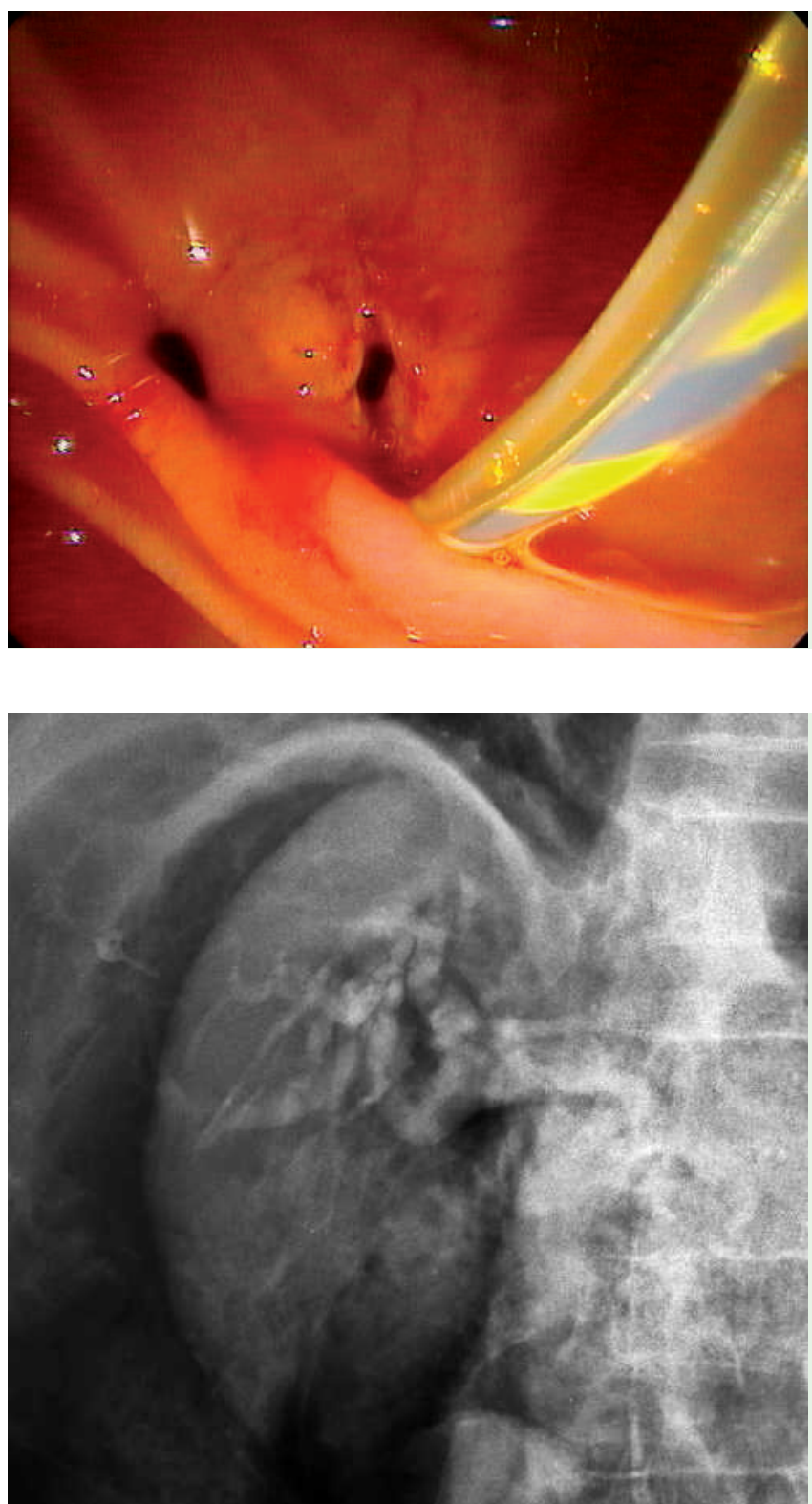

Fig. 1 After kneedle-knife-papillotomy, access to the common bile duct was gained.

was confirmed by a computed tomography $(\mathrm{CT})$ scan. When reviewing the record of the procedure ( $\bullet$ Video 1 ), it was observed that the NKP was extended a bit beyond the papillary mound, upwards in the endoscopic view, which corresponded to downwards in the real papillary anatomy. Following surgical consultation, a decision to operate was made due to the huge amount of retroperitoneal air present. During surgery only a pinpoint perforation was noted in the papillary area but no attempts to close it were made and a T-Kehr tube was inserted. The patient recovered well.

Most papillary perforations during ERCP due to sphincterotomy and precut access can be managed medically and do not need surgical intervention. Nevertheless, a team approach to management of such complications will ensure the best outcome [1]. In Billroth II anatomy it is important to remember that the endoscopic view is reversed and the common bile duct runs downwards. In addition, radiographs must be done at the end of the procedure.

Endoscopy_UCTN_Code_CPL_1AK_2AC

J. García-Cano ${ }^{1}$, M. Viñuelas-Chicano ${ }^{1}$,

E. Marqués-Medina², C. J. Gómez-Ruiz ${ }^{1}$

Section of Digestive Diseases, Hospital

Virgen de la Luz, Cuenca, Spain

2 Department of Surgery, Hospital Virgen de la Luz, Cuenca, Spain

\section{References}

1 Enns R, Eloubeidi MA, Mergener $K$ et al. ERCP-related perforations: risk factors and management. Endoscopy 2002; 34: 293 298

Fig. 2 In radiographs taken at the end of the procedure, the right kidney silhouette was clearly delineated and a retroperitoneal perforation was suspected.

Bibliography

DOI $10.1055 / \mathrm{s}-2007-995542$

Endoscopy 2008; 40: E84

(c) Georg Thieme Verlag KG Stuttgart · New York ISSN 0013-726X

Corresponding author

\section{J. García-Cano MD}

Section of Digestive Diseases

Hospital Virgen de la Luz

16002 Cuenca, Spain

Fax: +34-969-230407

j.garcia-cano@terra.es

\section{Video 1}

The kneedle-knife-papillotomy orifice was extended a bit beyond the papillary mound, upwards in the endoscopic view, which corresponded to downwards in the real papillary anatomy, causing the perforation. 